\title{
Article \\ Cubic Nanoparticles for Magnetic Hyperthermia: Process Optimization and Potential Industrial Implementation
}

\author{
Omar Sánchez Sánchez ${ }^{1}$, Teresa Castelo-Grande ${ }^{2}$, Paulo A. Augusto ${ }^{1,3, * \mathbb{C}}$, José M. Compaña ${ }^{4}$ \\ and Domingos Barbosa 2 (D) \\ 1 Departamento de Ingeniería Química y Textil, Facultad de Ciencias Químicas, Universidad de Salamanca, \\ Plaza de los Caídos, 1-5, 37008 Salamanca, Spain; jovvicpl@aeiou.pt \\ 2 LEPABE-Laboratory for Process Engineering, Environment, Biotechnology and Energy, Faculty of \\ Engineering, University of Porto, 4200-465 Porto, Portugal; tcg@fe.up.pt (T.C.-G.); dbarbosa@fe.up.pt (D.B.) \\ 3 Instituto de Biología Molecular y Celular del Cáncer, Campus Miguel de Unamuno, CSIC/Universidad \\ de Salamanca (GIR Citómica), 37007 Salamanca, Spain \\ 4 Servicio de Difracción de Rayos-X, Universidad de Salamanca, Pza. de Los Caídos s/n, \\ 37008 Salamanca, Spain; jmcompana@usal.es \\ * Correspondence: pauloaugusto@usal.es
}

check for

updates

Citation: Sánchez, O.S.; CasteloGrande, T.; Augusto, P.A.; Compaña, J.M.; Barbosa, D. Cubic Nanoparticles for Magnetic Hyperthermia: Process Optimization and Potential Industrial Implementation. Nanomaterials 2021, 11, 1652. https://doi.org/10.3390/ nano11071652

Academic Editors: Angelo Ferraro and Claire Wilhelm

Received: 4 May 2021

Accepted: 17 June 2021

Published: 23 June 2021

Publisher's Note: MDPI stays neutral with regard to jurisdictional claims in published maps and institutional affiliations.

Copyright: (c) 2021 by the authors. Licensee MDPI, Basel, Switzerland. This article is an open access article distributed under the terms and conditions of the Creative Commons Attribution (CC BY) license (https:/ / creativecommons.org/licenses/by/ $4.0 /)$.

\begin{abstract}
Cubic nanoparticles are referred to as the best shaped particles for magnetic hyperthermia applications. In this work, the best set of values for obtaining optimized shape and size of magnetic particles (namely: reagents quantities and proportions, type of solvents, temperature, etc.) is determined. A full industrial implementation study is also performed, including production system design and technical and economic viability.
\end{abstract}

Keywords: magnetic hyperthermia; magnetic nanoparticles; optimization; economic analysis; plant design and process engineering; cubic particles

\section{Introduction}

According to the World Health Organization (WHO), cancer is the main cause of death in the world, having been responsible for 9.6 million of deaths in 2018. In the next two decades, the increase in the number of cases is expected to be $60 \%$, according to a new WHO report [1]. Thus, research in oncology is extremely important to develop therapies to treat this disease and increase the expectation and quality of life of patients. Currently, the main treatments are based on surgery, radiotherapy, and chemotherapy. Thus, these techniques have concentrated most of the research and development till now. Nevertheless, the known side effects of these treatments have not been completely eliminated yet. Due to all this, the search for more efficient techniques and more specific action, with fewer unwanted effects, is important in promoting a better quality of life for patients. Various types of complementary therapies exist and are continuously being developed. In particular, the so-called hyperthermia therapies, which take advantage of the fact that tumor cells have a lower thermal tolerance than healthy cells [2]. In fact, hyperthermia is a therapeutic procedure in which tissues/cells are heated above normal physiological ranges (between 41 and $46^{\circ} \mathrm{C}$ ) in order to kill tumor or sensitize cells to increase the efficiency of standard therapies.

A more recent modality is magnetic hyperthermia (MHT) [3-6], where the increase in temperature occurs by applying alternating magnetic fields to a magnetic material with specific characteristics. In fact, the use of Magnetic Nanoparticles (MNPs) in medicine allows to treat hard-to-reach regions of the body. Chemical manipulation at a nanoscale size has conferred the ability to conjugate biomolecules, such as antibodies, with magnetic particles, for a more effective therapy or to achieve a specific goal, making MNPs ideal vehicles for new therapies based on localized and selective heat dissipation. Thus, MNPs can simultaneously combine various therapeutic functionalities, such as drug carriers, 
contrast agents in magnetic resonance imaging, or magnetic heating agents. Although MHT has been incorporated into clinical practice to treat a relatively wide range of types of cancer (prostate, esophagus, brain, etc.), today, it has shown to be advantageous in the treatment of sarcomas, carcinomas, and lymphomas.

The ability of the magnetic nanoparticles to generate heat when subjected to alternating magnetic fields is the basis of MHT. In fact, when exposed to an alternating magnetic field, MNPs produce heat through two main mechanisms [7]: hysteresis loss and Néel and Brown relaxation loss. Hysteresis losses occur in large MNPs that have multiple domains, while relaxation losses occur mainly in single domain MNPs.

Magnetite (iron oxide) particles are well-known for their biocompatibility, possible monodispersity and easiness of synthesis [7-9]. Besides, mono-domain particles are usually easy to obtain. Shape and size are important characteristics and it has been proven that critical size of magnetite to form multidomain structure is between 76 and $80 \mathrm{~nm}$ for cubic-shaped particles and $128 \mathrm{~nm}$ for spherical particles [10]. Supermagnetic behavior is known to exist, at least, below 50-20 nm for magnetite particles, depending on their shape and other characteristics [11-13]. Besides, SAR values (Specific Absorption Rate) for cubicshaped particles have been shown to be higher than the ones presented by spherical-shaped particles [14,15]. The correlation between particles microstructure and MHT response has been demonstrated (e.g., [16-18]).

The main methods to produce MNPs are coprecipitation, thermal decomposition, microemulsion, sol-gel, hydrothermal synthesis, and synthesis with polyols [8,9]. These methods have been used to prepare particles with an appropriate composition and size distribution, according to the application in mind. For example, for environmental nonspecific treatments, coprecipitation is usually the preferred method [8,19-23], while for biomedical applications where monodispersed particles are usually required, less simple methods, like thermal decomposition and hydrothermal, are preferred [8]. A summary of the main methods and their characteristics is presented in Table 1.

Table 1. Comparison between selected magnetic nanoparticle manufacturing methods.

\begin{tabular}{|c|c|c|c|c|c|c|c|c|}
\hline $\begin{array}{l}\text { Manufacturing } \\
\text { Method }\end{array}$ & Synthesis & $\begin{array}{l}\text { Reaction } \\
\text { Temp. }\left({ }^{\circ} \mathrm{C}\right)\end{array}$ & $\begin{array}{l}\text { Reaction } \\
\text { Time }\end{array}$ & Solvent & $\begin{array}{l}\text { Surface- } \\
\text { Capping } \\
\text { Agents }\end{array}$ & $\begin{array}{c}\text { Size } \\
\text { Distribution }\end{array}$ & $\begin{array}{l}\text { Shape } \\
\text { Control }\end{array}$ & Yield \\
\hline Coprecipitation & $\begin{array}{l}\text { Very } \\
\text { simple }\end{array}$ & $20-90$ & Minutes & Water & $\begin{array}{l}\text { During/after } \\
\text { reaction }\end{array}$ & $\begin{array}{l}\text { Relatively } \\
\text { narrow }\end{array}$ & Not good & High \\
\hline Microemulsion & Complicated & $20-50$ & Hours & Organic agents & During reaction & $\begin{array}{l}\text { Relatively } \\
\text { narrow }\end{array}$ & Good & Low \\
\hline $\begin{array}{c}\text { Thermal } \\
\text { decomposition }\end{array}$ & Complicated & $100-320$ & $\begin{array}{l}\text { Hours- } \\
\text { days }\end{array}$ & Organic agents & During reaction & Very narrow & Very good & High \\
\hline Hydrothermal & Simple & $200-250$ & $\begin{array}{l}\text { Hours- } \\
\text { days }\end{array}$ & Water-ethanol & During reaction & Very narrow & Very good & Medium \\
\hline Poliol & Simple & $\begin{array}{l}\text { 25-Boiling } \\
\text { Point }\end{array}$ & Hours & Ethylene PEG & During reaction & Narrow & Very Good & High \\
\hline
\end{tabular}

In the case of magnetic hyperthermia, magnetic nanoparticles must present good size distribution, good shape control, and a good SAR generation capability.

Most of the published literature is concerned with laboratorial methods to produce magnetic nanoparticles for hyperthermia applications, but, so far, to the best of our knowledge, none has studied the economic and technological viability of the scale-up of the method and its possible application at large-scale industrial production (which is an important step towards its widespread production and availability, especially after the recent license of a real medical clinical application of magnetic hyperthermia). This will also limit the number of producing methods that may be selected, as the method must be easily scalable (a fundamental characteristic for a production plant). 
The present work is concerned with the maximization of the magnetic hyperthermia capabilities of the particles, without increasing the costs to an unbearable level. Thus, the goal is to produce cubic magnetic nanoparticles with sizes lower than the monodomain critical value and, if possible, the supermagnetism critical value. The optimization of the main variables (ramp-up temperature, stirring speed, type of solvent, proportions of raw materials) for the selected method of production is one of the goals. The other goal is to study the economic and technological viability of the production, in order to set the path for future industrial implementation to support clinical widespread applications.

\section{Materials and Methods}

\subsection{Reagents}

In this study was used: iron (III) acetylacetonate (99\%) from Sigma Aldrich (St. Louis, MO, USA), oleic acid (90\%) from Panreac (Barcelona, Spain), benzyl ether (99\%) from Sigma Aldrich (Madrid, Spain), 4-biphenylcarboxylic acid (99\%) from Sigma Aldrich (Madrid, Spain), toluene (99.8\%) from Panreac (Barcelona, Spain), hexane (99\%) from Panreac (Barcelona, Spain), chloroform (99.9\%) from Panreac (Barcelona, Spain), and nitrogen (99\%) from Air Liquide (Paris, France). All solutions were made with distilled water.

\subsection{General Experimental Methodology}

\subsubsection{Synthesis of Cubic Magnetic Nanoparticles}

For the synthesis of the magnetic nanoparticles, the method developed by Kim et al. in 2008 [24] was followed, which gives rise to MNPs with cubic morphology and with sizes close to the critical size of the superparamagnetic state. In a typical synthesis of magnetite nanocubes, $2 \mathrm{mmol}$ of iron acetylacetonate $\left(\mathrm{Fe}(\mathrm{acac})_{3}\right)-\mathrm{Fe}\left(\mathrm{C}_{5} \mathrm{H}_{7} \mathrm{O}_{2}\right)_{3}$, $4.5 \mathrm{mmol}$ of oleic acid $\left(\mathrm{C}_{18} \mathrm{H}_{34}\right)$, and $52.5 \mathrm{mmol}$ of benzyl ether $-\mathrm{C}_{14} \mathrm{H}_{14} \mathrm{O}-$ (or $2 \mathrm{mmol}$ of 4-biphenylcarboxylic acid - $\mathrm{C}_{13} \mathrm{H}_{10} \mathrm{O}_{2}$-depending on the size and shape) were used. The initial mixture is first degassed with nitrogen gas. Then, temperature is risen up to $290{ }^{\circ} \mathrm{C}$ at a temperature gradient ramp-up of about $20^{\circ} \mathrm{C} / \mathrm{min}$, under energetic stirring. Once the final temperature is reached, the reaction remains at $290^{\circ} \mathrm{C}$ for $30 \mathrm{~min}$. At the end of the process, the sample is cooled and a mixture of toluene and hexane in a 4:1 volumetric ratio is added, and the sample centrifuged at $1700 \mathrm{rpm}$. Finally, chloroform is used to clean the particles. The main reaction that occurs at these conditions is:

$$
\mathrm{aFe}\left(\mathrm{C}_{5} \mathrm{H}_{7} \mathrm{O}_{2}\right)_{3}+\mathrm{bC}_{18} \mathrm{H}_{34}+\mathrm{cC}_{13} \mathrm{H}_{10} \mathrm{O}_{2} / \mathrm{dC}_{14} \mathrm{H}_{14} \mathrm{O} \rightarrow \mathrm{eFe}_{3} \mathrm{O}_{4}+\text { Subproducts }
$$

The steps of the reaction process are represented in Figure 1.

\subsubsection{Particles' Characterization}

Particles were characterized by determining their magnetic properties, size, and shape and percentage of magnetite. Hence, to certify the percentage of obtained magnetite, X-ray studies were made (X-ray diffraction (XRD) Bruker D8 Advance, Karlsruhe, Germany); to determine the morphology and size of the particles, Scanning Electron Microscopy (SEM) (JEOL JSM-840, Madrid, Spain) was performed; finally, to access magnetic susceptibility, samples were analyzed with a Kappabridge KLY-4 susceptometer (a semiautomatic auto balance inductivity bridge, Porto, Portugal). 


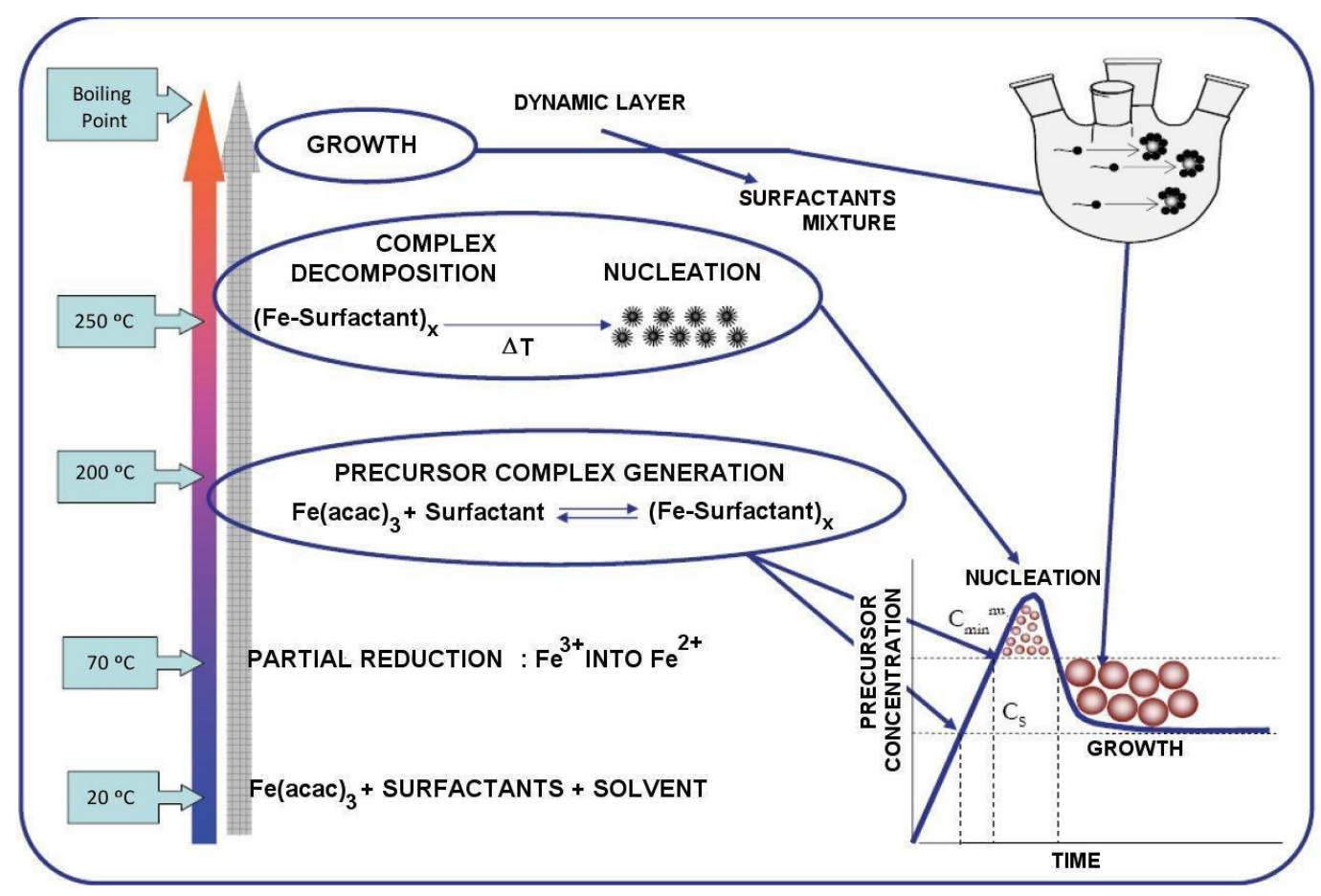

Figure 1. Reaction mechanism—based on [25].

\subsubsection{Influence of the Main Variables}

For all these experiments, the default options are: iron acetylacetonate (III) $-2 \mathrm{mmol}$; oleic acid-4.5 mmol; 4-biphenylcarboxylic acid-2 mmol; stirring-200 rpm; reaction temperature-290 ${ }^{\circ} \mathrm{C}$; temperature ramp-up: $20^{\circ} \mathrm{C} / \mathrm{min}$; centrifugal speed-1700 rpm. The analyzed variables were:

(a) Effect of mechanical stirring (four values were used: 150, 170, 200, and $220 \mathrm{rpm}$ ).

(b) Effect of temperature ramp-up (the increasing temperature gradients studied were: $15,20,25$, and $30^{\circ} \mathrm{C} / \mathrm{min}$ ).

(c) Effect of the type of solvent (the solvents studied were: (a) 4-biphenylcarboxylic acid-2 mmol; (b) benzyl ether- $52.5 \mathrm{mmol}$; (c) both solvents: 4-biphenylcarboxylic acid-2 mmol—and benzyl ether- $52.5 \mathrm{mmol}$ ).

(d) Effect of reagents ratio (the ratios studied were: doubling oleic acid amount, doubling 4-biphenylcarboxylic acid amount, and doubling all reagents).

(e) Degassing time (the degassing time with nitrogen was reduced by half).

In Table 2 are shown the values used in each experiment. It is important to notice that experiment 7 corresponds to the predetermined conditions with similar results to those already presented in literature, thus no results are presented here. 


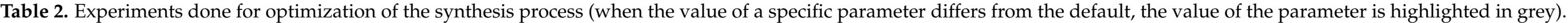

\begin{tabular}{|c|c|c|c|c|c|c|c|c|c|}
\hline \multirow[b]{2}{*}{ Experiment } & \multicolumn{9}{|c|}{ Reagent/Property } \\
\hline & $\begin{array}{c}\text { Iron } \\
\text { Acetylacetonate } \\
\text { (III) (mmol) }\end{array}$ & $\begin{array}{l}\text { Oleic Acid } \\
\text { (mmol) }\end{array}$ & $\begin{array}{l}\text { 4-Biphenylcarboxylic } \\
\text { Acid (mmol) }\end{array}$ & $\begin{array}{l}\text { Benzyl ether } \\
\text { (mmol) }\end{array}$ & $\begin{array}{c}\text { Reaction } \\
\text { Temperature } \\
\left({ }^{\circ} \mathrm{C}\right)\end{array}$ & $\begin{array}{c}\text { Temperature } \\
\text { Ramp-Up } \\
\left({ }^{\circ} \mathrm{C} / \mathrm{min}\right)\end{array}$ & $\begin{array}{c}\text { Stirring } \\
\text { Speed (rpm) }\end{array}$ & $\begin{array}{l}\text { Centrifuge } \\
(\mathrm{rpm})\end{array}$ & Degassing \\
\hline 2 & 2 & 4.5 & 2 & - & 290 & 20 & 170 & 1700 & Normal \\
\hline 3 & 2 & 4.5 & 2 & - & 290 & 20 & 220 & 1700 & Normal \\
\hline 4 & 2 & 4.5 & 2 & - & 290 & 25 & 220 & 2000 & Normal \\
\hline 5 & 2 & 4.5 & 2 & - & 290 & 15 & 220 & 2000 & Normal \\
\hline 7 & 2 & 4.5 & - & 52.5 & 290 & 15 & 200 & 2500 & Normal \\
\hline 8 & 2 & 4.5 & - & 52.5 & 290 & 20 & 200 & 2500 & Normal \\
\hline 9 & 2 & 4.5 & - & 52.5 & 290 & 25 & 200 & 2500 & Normal \\
\hline 10 & 2 & 4.5 & 2 & - & 290 & 20 & 220 & 2500 & Normal \\
\hline $11\left(^{*}\right)$ & 4 & 9 & 4 & - & 290 & 25 & 200 & 2500 & Normal \\
\hline $12(* *)$ & 2 & 4.5 & 2 & 52.5 & 290 & 25 & 200 & 2500 & Normal \\
\hline 13 & 2 & 4.5 & 2 & - & 290 & 30 & 200 & 2500 & Half \\
\hline 14 & 2 & 4.5 & 2 & 52.5 & 290 & 25 & 200 & 2500 & Normal \\
\hline 15 & 2 & 9 & 2 & - & 290 & 20 & 200 & 2500 & Normal \\
\hline
\end{tabular}

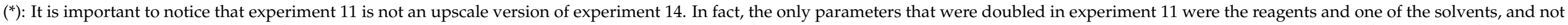

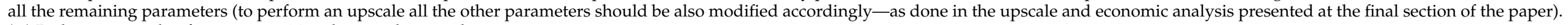

${ }^{(*)}$ Preliminary study of experiment 14 with coincident results. 


\subsubsection{Economic Analysis and Industrial Scale-Up Study}

The following methodological steps were applied for the economic analysis and industrial scale-up [8]: (a) determine the optimized process for magnetic hyperthermia; (b) perform a market study to determine the demand of the product (magnetic nanoparticles) for hyperthermia applications; (c) determine the size of the plant; (d) analyze all the process steps, choose all the process units and perform all the mass and energy balances required in the plant; (e) detailed scale-up design of the main equipment; and (f) analyze the global economic impact and profitability.

\subsection{Instrumentation}

The main instrumentation used was: Three-way Reactor (Nahita, Madrid), Orbital stirrer (Nahita, Madrid), Thermal Heater (Nahita, Madrid), Centrifuge (Fischer, Barcelona), besides regular laboratory glass material.

\section{Results and Discussion}

In order to determine the best set of values for the main producing parameters, the obtained particles need to be analyzed and compared according to their main characteristics. In this context, it is important to analyze: magnetic properties (magnetic susceptibility), phase composition or phase distribution ratio (XRD), particle size, and morphology (SEM).

\subsection{Magnetic Properties}

In Table 3 are shown the results obtained for the magnetic properties of the final product corresponding to each experiment.

Table 3. Magnetic properties of the produced nanoparticles.

\begin{tabular}{|c|c|c|c|c|c|c|c|c|}
\hline Experiment Number & 1 & 2 & 3 & 4 & 5 & 6 & 7 & 8 \\
\hline Magnetic susceptibility (SI) & $2.51 \times 10^{-4}$ & $5.29 \times 10^{-4}$ & $2.84 \times 10^{-4}$ & $1.56 \times 10^{-4}$ & $1.51 \times 10^{-4}$ & $2.56 \times 10^{-4}$ & $9.71 \times 10^{-5}$ & $2.00 \times 10^{-4}$ \\
\hline Experiment number & 9 & 10 & 11 & 12 and 14 & 13 & 15 & 16 & \\
\hline Magnetic susceptibility (SI) & $2.13 \times 10^{-4}$ & $9.25 \times 10^{-5}$ & $4.64 \times 10^{-4}$ & $3.12 \times 10^{-4}$ & $2.44 \times 10^{-4}$ & - & - & \\
\hline
\end{tabular}

As it may be seen, the large majority of the obtained nanoparticles present the same order of magnitude for the magnetic susceptibly. However, particles obtained in experiments $2,11,12$, and 14 present the highest values, while the lowest values were obtained for experiments 7 and 10 .

\subsection{Composition}

Concerning their structure, $\mathrm{X}$-ray analysis were made on all particles obtained from the set of the performed experiments. In Figure 2 is presented one of the diffraction patterns obtained for these. They all are almost coincident and present the same peaks, so they may be represented by the one depicted in Figure 2 (except for experiment 15 and 16 for which no analysis was possible to be done due to the nature of the obtained products). The typical magnetite peaks are shown in red, according to Powder Diffraction File PDF2 dataset \#821533 (Powder Diffraction File, International Centre for Diffraction Data, Newtown Square, PA, USA). No additional peaks are found, so samples are essentially pure magnetite.

In addition to the qualitative analysis, an estimation of the crystallite size was calculated by using the Scherrer equation (Table 4). The main peak (at ca. $35.5^{\circ}$ ) was used for the calculations. Lanthanum hexaboride (NIST-660b) was used as crystalline standard for instrumental broadening. 
Table 4. Estimation of the crystallite size (calculated by using the Scherrer equation).

\begin{tabular}{ccccccccc}
\hline Experiment Number & $\mathbf{1}$ & $\mathbf{2}$ & $\mathbf{3}$ & $\mathbf{4}$ & $\mathbf{5}$ & $\mathbf{6}$ & $\mathbf{7}$ & $\mathbf{8}$ \\
\hline $\mathrm{D}(\mathrm{nm})$ & 73 & 50 & 44 & 39 & 32 & 37 & 88 & 92 \\
\hline Experiment number & $\mathbf{9}$ & $\mathbf{1 0}$ & $\mathbf{1 1}$ & $\mathbf{1 2}$ and $\mathbf{1 4}$ & $\mathbf{1 3}$ & $\mathbf{1 5}$ & $\mathbf{1 6}$ & \\
\hline $\mathrm{D}(\mathrm{nm})$ & 121 & 36 & 54 & 32 & 50 & - & - & \\
\hline
\end{tabular}

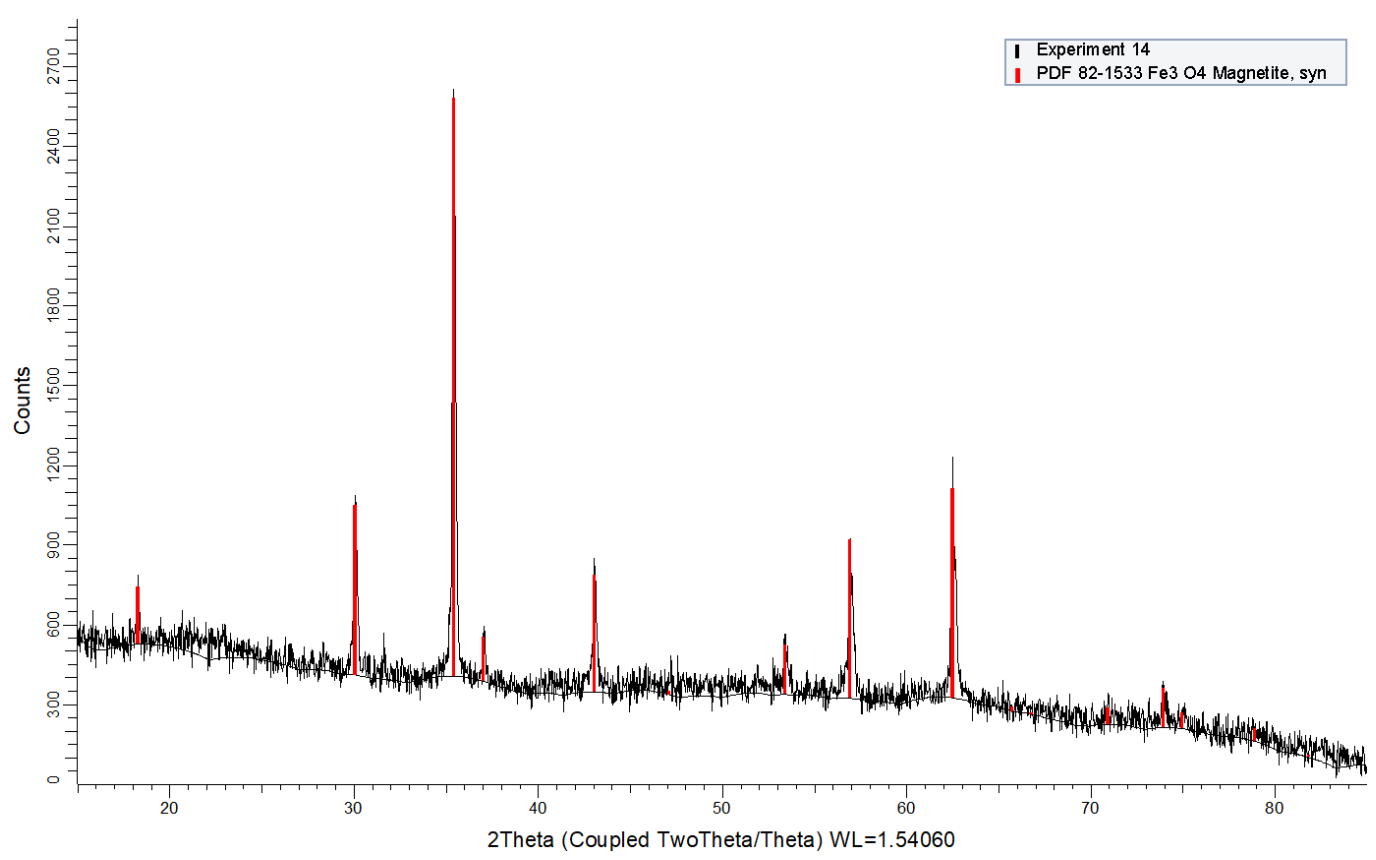

Figure 2. X-ray of experiment 14.

\subsection{Particle Size and Morphology}

In Figure 3 are presented the secondary electron SEM images of the particles obtained in experiments 1-14, while in Table 5 are presented their size ranges percentages, extracted from the corresponding histograms shown in Supplementary Materials. For some particles, high-quality images were not possible to obtain, mostly due to charging, even after gold sputter coating. In spite of this setback, relevant data were obtained, as summarized in Tables 5 and 6 . Some general comments may be emphasized. Typically, when poorly shaped particles are obtained, some tendency to large agglomeration is present, maybe suggesting some kind of growth interference (e.g., Figure 3a,d). When moderately shaped particles are attained, there is a tendency for euhedral forms, almost cubic, though occasional octahedra may be present (e.g., some triangles in Figure 3k), but no rhombic-dodecahedra have been detected. At last, when well-shaped forms are obtained, there is an undoubted preference for cubes and parallelepipeds, in accordance to the results of Kim et al. 2008 [24]. Some stacking is observed (e.g., Figure $3 g-i)$, but it has to be underlined that twinning is not detected in any well-shaped sample. 


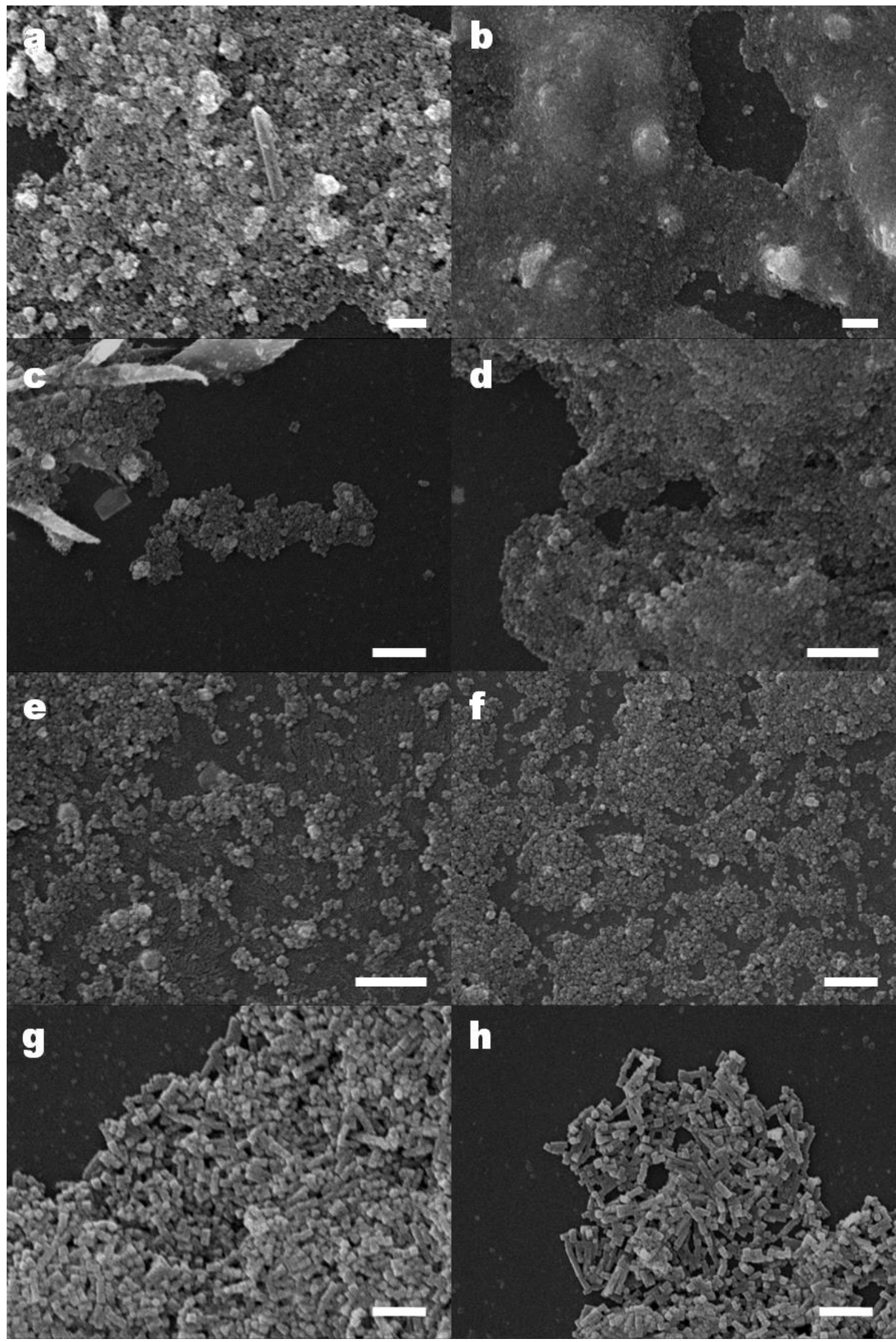

Figure 3. Cont. 


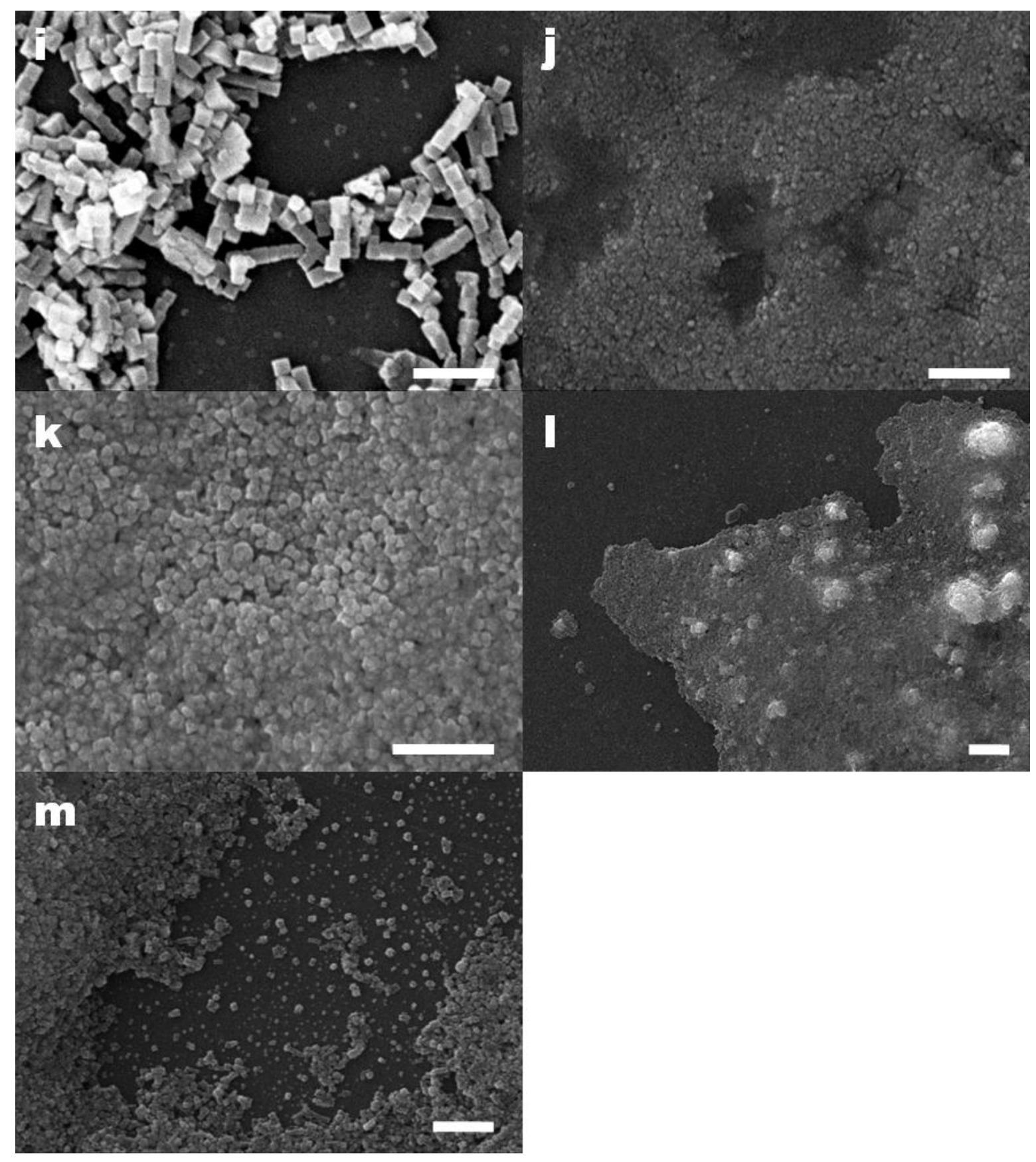

Figure 3. SEM of the nanomagnetite particles obtained in experiments: (a) 1 ; (b) 2 ; (c) 3 ; (d) 4 ; (e) 5 ; (f) 6 ; (g) 7 ; (h) 8 ; (i) 9 ; (j) $10 ;(\mathbf{k}) 11 ;(\mathbf{l}) 13 ;(\mathbf{m}) 12$ and 14 . White bar length $=1 \mu \mathrm{m}$. 
Table 5. Size ranges percentages of each experiment product. The size ranges showing highest percentage are highlighted for each case: light grey- between 10-19\%; medium gray- between 20-29\%; dark grey- more than 30\%.

\begin{tabular}{|c|c|c|c|c|c|c|c|c|c|c|c|c|}
\hline $\begin{array}{c}\text { Exp. } \\
\text { Number }\end{array}$ & $\begin{array}{c}10-20 \\
(\mathrm{~nm})\end{array}$ & $\begin{array}{c}20-28 \\
(\mathrm{~nm})\end{array}$ & $\begin{array}{c}28-36 \\
(\mathrm{~nm})\end{array}$ & $\begin{array}{c}36-44 \\
(\mathrm{~nm})\end{array}$ & $\begin{array}{l}44-52 \\
(\mathrm{~nm})\end{array}$ & $\begin{array}{c}52-60 \\
(\mathrm{~nm})\end{array}$ & $\begin{array}{c}60-68 \\
(\mathrm{~nm})\end{array}$ & $\begin{array}{l}68-76 \\
(\mathrm{~nm})\end{array}$ & $\begin{array}{c}76-84 \\
(\mathrm{~nm})\end{array}$ & $\begin{array}{c}84-92 \\
(\mathrm{~nm})\end{array}$ & $\begin{array}{c}\text { 92-100 } \\
(\mathrm{nm})\end{array}$ & $\begin{array}{l}>100 \\
(\mathrm{~nm})\end{array}$ \\
\hline 1 & $0 \%$ & $0 \%$ & $0 \%$ & $0 \%$ & $0 \%$ & $0 \%$ & $1 \%$ & $2 \%$ & $3 \%$ & $2 \%$ & $12 \%$ & $80 \%$ \\
\hline 2 & $0 \%$ & $0 \%$ & $0 \%$ & $0 \%$ & $2 \%$ & $8 \%$ & $8 \%$ & $9 \%$ & $14 \%$ & $14 \%$ & $13 \%$ & $32 \%$ \\
\hline 3 & $0 \%$ & $0 \%$ & $4 \%$ & $15 \%$ & $24 \%$ & $27 \%$ & $15 \%$ & $12 \%$ & $1 \%$ & $0 \%$ & $2 \%$ & $0 \%$ \\
\hline 4 & $0 \%$ & $5 \%$ & $12 \%$ & $28 \%$ & $26 \%$ & $18 \%$ & $7 \%$ & $2 \%$ & $0 \%$ & $2 \%$ & $0 \%$ & $0 \%$ \\
\hline 5 & $0 \%$ & $3 \%$ & $12 \%$ & $25 \%$ & $26 \%$ & $14 \%$ & $9 \%$ & $6 \%$ & $3 \%$ & $1 \%$ & $2 \%$ & $0 \%$ \\
\hline 6 & $0 \%$ & $6 \%$ & $24 \%$ & $25 \%$ & $17 \%$ & $17 \%$ & $5 \%$ & $2 \%$ & $2 \%$ & $2 \%$ & $0 \%$ & $0 \%$ \\
\hline 7 & $0 \%$ & $0 \%$ & $0 \%$ & $0 \%$ & $1 \%$ & $4 \%$ & $4 \%$ & $11 \%$ & $12 \%$ & $12 \%$ & $10 \%$ & $46 \%$ \\
\hline 8 & $0 \%$ & $0 \%$ & $0 \%$ & $0 \%$ & $0 \%$ & $1 \%$ & $1 \%$ & $3 \%$ & $3 \%$ & $3 \%$ & $7 \%$ & $82 \%$ \\
\hline 9 & $0 \%$ & $0 \%$ & $0 \%$ & $0 \%$ & $0 \%$ & $0 \%$ & $0 \%$ & $0 \%$ & $1 \%$ & $2 \%$ & $4 \%$ & $93 \%$ \\
\hline 10 & $0 \%$ & $11 \%$ & $9 \%$ & $19 \%$ & $30 \%$ & $18 \%$ & $9 \%$ & $4 \%$ & $0 \%$ & $0 \%$ & $0 \%$ & $0 \%$ \\
\hline 11 & $0 \%$ & $4 \%$ & $13 \%$ & $18 \%$ & $16 \%$ & $20 \%$ & $10 \%$ & $13 \%$ & $2 \%$ & $3 \%$ & $2 \%$ & $0 \%$ \\
\hline 12,14 & $6 \%$ & $26 \%$ & $32 \%$ & $16 \%$ & $9 \%$ & $5 \%$ & $4 \%$ & $1 \%$ & $1 \%$ & $0 \%$ & $0 \%$ & $0 \%$ \\
\hline 13 & $0 \%$ & $4 \%$ & $6 \%$ & $6 \%$ & $15 \%$ & $20 \%$ & $24 \%$ & $12 \%$ & $5 \%$ & $5 \%$ & $4 \%$ & $3 \%$ \\
\hline 15 & - & - & - & - & - & - & - & 一 & - & - & & \\
\hline 16 & - & - & - & - & - & - & - & - & - & - & & \\
\hline
\end{tabular}

Table 6. Main conclusions from the obtained results.

\begin{tabular}{|c|c|c|c|c|}
\hline $\begin{array}{l}\text { Exp. } \\
\text { Number }\end{array}$ & Morphology & Main Size Ranges & $\begin{array}{l}\text { Magnetic } \\
\text { Character }\end{array}$ & Conclusions \\
\hline 1 & Undefined & $\begin{array}{l}92-100 \mathrm{~nm}: 12 \% \\
>100 \mathrm{~nm}: 80 \%\end{array}$ & Regular & $\begin{array}{l}\text { The low resolution does not allow to } \\
\text { determine their precise morphology. Size } \\
\text { much larger than desired. Presents some } \\
\text { large agglomerations. }\end{array}$ \\
\hline 2 & Undefined & $\begin{array}{l}76-84 \mathrm{~nm}: 14 \% \\
84-92 \mathrm{~nm}: 14 \% \\
92-100 \mathrm{~nm}: 13 \% \\
>100 \mathrm{~nm}: 32 \%\end{array}$ & Slightly Higher & $\begin{array}{l}\text { The low resolution does not allow to } \\
\text { determine their precise morphology. Size } \\
\text { much larger than desired. Presents some } \\
\text { large agglomerations. }\end{array}$ \\
\hline 3 & $\begin{array}{l}\text { Generally irregular. } \\
\text { Some cubic-shaped } \\
\text { particles are present. }\end{array}$ & $\begin{array}{l}36-44 \mathrm{~nm}: 15 \% \\
44-52 \mathrm{~nm}: 24 \% \\
52-60 \mathrm{~nm}: 27 \% \\
60-68 \mathrm{~nm}: 15 \% \\
68-76 \mathrm{~nm}: 12 \%\end{array}$ & Regular & $\begin{array}{l}\text { Acceptable morphology. Size larger than } \\
\text { desired. Some large agglomerations are } \\
\text { present. }\end{array}$ \\
\hline 4 & Irregular & $\begin{array}{l}28-36 \mathrm{~nm}: 12 \% \\
36-44 \mathrm{~nm}: 28 \% \\
44-52 \mathrm{~nm}: 26 \% \\
52-60 \mathrm{~nm}: 18 \%\end{array}$ & Regular & $\begin{array}{l}\text { Poorly defined morphology. Size slightly } \\
\text { larger than desired. Small agglomerations } \\
\text { of medium size are seen. }\end{array}$ \\
\hline 5 & Irregular & $\begin{array}{l}28-36 \mathrm{~nm}: 12 \% \\
36-44 \mathrm{~nm}: 25 \% \\
44-52 \mathrm{~nm}: 26 \% \\
52-60 \mathrm{~nm}: 14 \%\end{array}$ & Regular & $\begin{array}{l}\text { Poorly defined morphology. Size slightly } \\
\text { larger than desired. Small agglomerations } \\
\text { of medium size are seen. }\end{array}$ \\
\hline 6 & $\begin{array}{l}\text { Generally irregular. } \\
\text { Some cubic-shaped } \\
\text { particles are present. }\end{array}$ & $\begin{array}{l}28-36 \mathrm{~nm}: 24 \% \\
36-44 \mathrm{~nm}: 25 \% \\
44-52 \mathrm{~nm}: 17 \% \\
52-60 \mathrm{~nm}: 17 \% \\
68-76 \mathrm{~nm}: 11 \%\end{array}$ & Regular & $\begin{array}{l}\text { Acceptable morphology. Size slightly } \\
\text { larger than desired. Some agglomerations } \\
\text { of medium size are seen. }\end{array}$ \\
\hline 7 & $\begin{array}{l}\text { Cubic/cobblestone } \\
\text { particles }\end{array}$ & $\begin{array}{l}76-84 \mathrm{~nm}: 12 \% \\
84-92 \mathrm{~nm}: 12 \% \\
92-100 \mathrm{~nm}: 10 \% \\
>100 \mathrm{~nm}: 46 \%\end{array}$ & Slightly Lower & $\begin{array}{l}\text { Ideal morphology. Size much larger than } \\
\text { desired. There are no agglomerations. }\end{array}$ \\
\hline 8 & $\begin{array}{l}\text { Cubic/cobblestone } \\
\text { particles }\end{array}$ & >100 nm: $82 \%$ & Regular & $\begin{array}{l}\text { Ideal morphology. Size much larger than } \\
\text { desired. There are no agglomerations. }\end{array}$ \\
\hline 9 & $\begin{array}{l}\text { Cubic/cobblestone } \\
\text { particles }\end{array}$ & >100 nm: $93 \%$ & Regular & $\begin{array}{l}\text { Ideal morphology. Size much larger than } \\
\text { desired. There are no agglomerations. }\end{array}$ \\
\hline
\end{tabular}


Table 6. Cont

\begin{tabular}{|c|c|c|c|c|}
\hline $\begin{array}{l}\text { Exp. } \\
\text { Number }\end{array}$ & Morphology & Main Size Ranges & $\begin{array}{l}\text { Magnetic } \\
\text { Character }\end{array}$ & Conclusions \\
\hline 10 & $\begin{array}{l}\text { Generally irregular. } \\
\text { Some cubic-shaped } \\
\text { particles are present. }\end{array}$ & $\begin{array}{l}20-28 \mathrm{~nm}: 11 \% \\
28-36 \mathrm{~nm}: 9 \% \\
36-44 \mathrm{~nm}: 19 \% \\
44-52 \mathrm{~nm}: 30 \% \\
52-60 \mathrm{~nm}: 18 \% \\
28-36 \mathrm{~nm}: 13 \%\end{array}$ & Slightly Lower & $\begin{array}{l}\text { Acceptable morphology. Size slightly } \\
\text { larger than desired. Large agglomerations } \\
\text { are not visible. }\end{array}$ \\
\hline 11 & $\begin{array}{l}\text { Generally irregular. } \\
\text { Some cubic-shaped } \\
\text { particles are present. }\end{array}$ & $\begin{array}{l}36-44 \mathrm{~nm}: 18 \% \\
44-52 \mathrm{~nm}: 16 \% \\
52-60 \mathrm{~nm}: 20 \% \\
60-68 \mathrm{~nm}: 10 \% \\
68-76 \mathrm{~nm}: 13 \%\end{array}$ & Slightly Higher & $\begin{array}{l}\text { Acceptable morphology. Size slightly } \\
\text { larger than desired. There are several } \\
\text { medium-sized agglomerations }\end{array}$ \\
\hline 13 & Undefined & $\begin{array}{l}44-52 \mathrm{~nm}: 15 \% \\
52-60 \mathrm{~nm}: 20 \% \\
60-68 \mathrm{~nm}: 24 \% \\
68-76 \mathrm{~nm}: 12 \%\end{array}$ & Regular & $\begin{array}{l}\text { The low resolution does not allow to } \\
\text { determine their precise morphology. Size } \\
\text { much larger than required. Presents some } \\
\text { large agglomerations. }\end{array}$ \\
\hline 12 and 14 & $\begin{array}{l}\text { Generally cubic-shaped } \\
\text { particles are present. } \\
\text { Some irregular shape } \\
\text { also appears. }\end{array}$ & $\begin{array}{l}20-28 \mathrm{~nm}: 26 \% \\
28-36 \mathrm{~nm}: 32 \% \\
36-44 \mathrm{~nm}: 16 \%\end{array}$ & Slightly Higher & $\begin{array}{l}\text { Very good morphology. Very good size. } \\
\text { There are no agglomerations. }\end{array}$ \\
\hline 15 & No particles obtained & & & \\
\hline 16 & No particles obtained & & - & \\
\hline
\end{tabular}

\subsection{Discussion of Results}

In Table 6 is presented a summary of the main conclusions, considering all the results presented previously.

From Table 3, it may be concluded that except for the case of experiments 15 and 16 (where no particles are obtained), the particles present the same order of magnitude concerning magnetic properties (being experiments 2,11, 12, and 14 the ones that present particles with higher magnetic properties and 7 and 10 the ones that present particles with lower magnetic properties, by a ratio of 3-4). Clearly, the process is well behaved for the majority of parameters, does not pose serious threat to the attainment of magnetite crystals, and does not have a strong influence on their anisotropy and the alignment of magnetic moments. The exceptions are experiments 15 and 16, corresponding to the increase of the surfactant (oleic acid) and one of the tested solvents (4-biphenylcarboxylic acid), respectively.

Considering the attainment of the cubic shape, only experiments 3 (highest stirring), 6 (highest ramp-up temperature scale gradient), 10 (highest centrifuging speed), and 11 (doubling of all reagents quantities) are acceptable, and experiments 7, 8, 9 (all using benzyl ether as solvent), 12, and 14 (using both solvents-benzyl ether and 4-biphenylcarboxylic acid, highest centrifuging speed and high temperature ramp-up gradient) are ideal. Comparing the products of these last experiments, considering the size of the particles, it may be concluded that particles obtained in experiments 7,8, and 9 present a much larger size than desired (using benzyl ether as solvent alone is good for the shape, but not for obtaining small sizes); in experiments 3,6,10, and 11 the obtained particles present slightly larger size than desired and present agglomerations, while in experiments 12 and 14, obtained particles present the desired size and no agglomerations are observed. Therefore, steps followed to obtain particles in experiments 12 and 14 stand-out as the optimized particle production method, as these experiments present final cubic-shaped nanoparticles with high magnetic properties, with the desired size and no agglomerations. Hence, using both solvents at the same time (benzyl ether and 4-biphenylcarboxylic acid) and maintaining the selected base preferences for the other reagents and stirring speed (while increasing the centrifuging speed) seems to be the best option to obtain the desired magnetic nanoparticles. 


\subsubsection{Parameters Influence}

By analyzing each parameter, it may be concluded that:

(a) increasing stirring speed is beneficial (experiments 1, 2, and 3),

(b) increase in temperature ramp-up does not affect the results (experiments 4, 5, 6, 7, 8, 9 , and 10),

(c) substituting the solvent (4-biphenylcarboxylic acid by benzyl ether) improves the percentage of particles presenting a cubic form, but increases particle sizes (experiments 7,8 , and 9),

(d) doubling the quantities of oleic acid or 4-biphenylcarboxylic acid leads to a null production of particles (experiments 15 and 16),

(e) doubling the quantity of the two reactives and one of the tested solvents is not detrimental (experiment 11),

(f) reducing the degasification time is detrimental (experiment 13),

(g) using both solvents at the same time (4-biphenylcarboxylic acid and benzyl ether) improves the process (experiments 12 and 14).

\subsubsection{Ideal Value of the Parameters}

From all the above, it may be concluded that the ideal conditions are: iron acetylacetonate (III) - $2 \mathrm{mmol}$; oleic acid- $4.5 \mathrm{mmol}$; 4-biphenylcarboxylic acid—2 $\mathrm{mmol}$; benzyl ether-52.5 mmol; stirring $-200 \mathrm{rpm}$; reaction temperature $-290^{\circ} \mathrm{C}$; temperature rampup $-25^{\circ} \mathrm{C} / \mathrm{min}$; centrifugal speed $2500 \mathrm{rpm}$.

\section{Potential Industrial Implementation}

To determine the potential industrial implementation of the cubic magnetic nanoparticle manufacturing process, the methodology described in [8] is followed: first, determine the potential international demand of the product (magnetic nanoparticles for magnetic hyperthermia applications), then, determine the plant size, analyze all the process steps and chose all the process units (based on the mass and energy balances), perform a detailed scale-up design of the main equipment, and finally analyze the economic impact and profitability. By following this methodology it was possible to determine the technological and economic viability of the industrial implementation of the optimized process for production of cubic-shaped magnetite nanoparticles based on the optimized values found in Section 3. In what follows, only the main results are present (in Supplementary Material are given all the details concerning these calculations).

\subsection{Size of the Plant}

The minimum size of the plant in order to be profitable is $3850 \mathrm{~kg} /$ year.

The plant will be designed for an annual income of EUR 203,200,000, at a price of EUR $30,000 / \mathrm{kg}$ magnetic nanoparticles. The annual production is equivalent to $6773 \mathrm{~kg} /$ year.

\subsection{Process Engineering Design}

In Figure 4 is depicted the process diagram of the proposed industrial plant and in Supplementary Material the characteristics of each stream. 


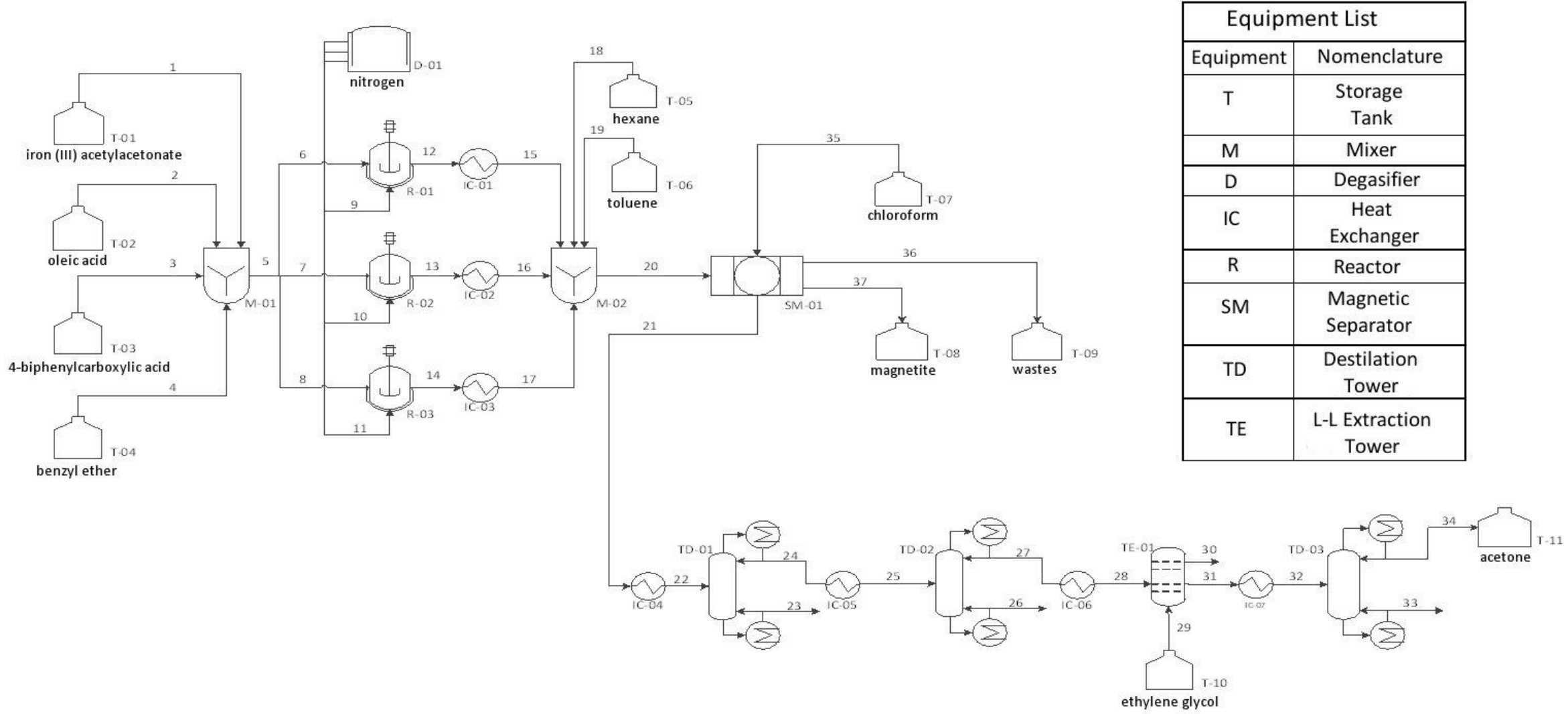

Figure 4. Process Engineering Flowsheet of the Plant to Produce Cubic-Shaped Magnetite Nanoparticles. 
The process begins in the M-01 mixer where the main components (stored in the T-01, T-02, T-03, and T-04 tanks) are mixed in their stoichiometric proportions. The main raw materials are: iron (III) acetylacetonate, which will act as the precursor agent, oleic acid, which will be the surfactant and intervenes in the ligand exchange reaction with iron acetylacetonate, and 4-biphenylcarboxylic acid and benzyl ether, which will act as solvents. When the raw materials have been mixed in the M-01, the mixture is taken to the R-01 reactor, as well as to reactors R-02 and R-03. In the reactors, the degassing is done with nitrogen delivered by the degasser D-01. The degassed mixture is then heated through a jacket heater up to $290{ }^{\circ} \mathrm{C}(563 \mathrm{~K})$, with a constant temperature ramp-up rate of $25^{\circ} \mathrm{C} / \mathrm{min}$ and a stirring of $800 \mathrm{rpm}$. When the mixture reaches $290^{\circ} \mathrm{C}$, it remains constant for $30 \mathrm{~min}$. Then, the sample is fed to the heat exchanger IC01, where it is cooled to room temperature. Subsequently, the mixture is introduced in the mixing container M-02 and a mixture of hexane and toluene is added, from tanks T-05 and T-06, with a ratio of 1:4, to facilitate the subsequent separation. The entire mixture is then passed through a magnetic separator SM-01, which is responsible for retaining the MNPs synthesized in the reactor. Lastly, the MNPs are cleaned with chloroform and stored in tank T-07. Regarding the remaining compounds, they are discarded by the magnetic separator through stream 21, including benzyl ether, hexane, toluene, and the other by-products (acetone), which are recycled to reduce raw material costs. For such an effect, distillation towers and a liquid-liquid extraction tower are used.

\subsection{Global Economic Impact and Profitability}

In Table 7 is presented a summary of the overall economic balance of the plant.

Table 7. Overall economic balance of industrial implementation of MNPs production for magnetic hyperthermia applications.

\begin{tabular}{lclc}
\hline \multicolumn{1}{c}{ Cost } & EUR & \multicolumn{1}{c}{ Invested Capital } & EUR \\
\hline 1.1 Raw Materials & $48,298,030$ & 1.1 Instrumentation & 827,043 \\
1.2 Direct Human Labor & 829,870 & 1.2 Initial Setup & 473,602 \\
1.3 Indirect Human Labor & 207,358 & 1.3 Piping and Valves & 372,270 \\
1.4 General Services & 580,909 & 1.4 Measuring and Control & 165,409 \\
1.5 Supplies & 80,096 & 1.5 Heat Isolation & 57,893 \\
1.6 Maintenance & 234,179 & 1.6 Electrical Installation & 124,057 \\
1.7 Laboratory & 165,974 & 1.7 Land and Structures & $1,122,893$ \\
1.8 Board and Technical Staff & 224,564 & 1.8 Auxiliary Facilities & 330,817 \\
1.9 Amortization & 82,704 & 1.9 Project and Design & 361,923 \\
1.10 Taxes and Insurances & 160,192 & 1.10 Constructor Hiring & 208,439 \\
TOTAL COST OF FABRICATION & $50,863,876$ & 1.11 Unexpected Expenses & 521,098 \\
2.1 Commercial Expenses & $10,172,775$ & 1.12 Preliminary Studies & $2,803,343$ \\
2.2 Management & 131,826 & 1.13 Preliminary Startup & 640,764 \\
2.3 Financial Expenses & $5,809,661$ & - & - \\
2.4 Research & 240,286 & TOTAL IMMOBILIZED & $8,009,550$ \\
2.5 Technical Services & $2,032,000$ & CIRCULATING CAPITAL & $21,038,753$ \\
TOTAL COST OF MANAGEMENT & $18,386,548$ & TOTAL INVESTED CAPITAL & $29,048,303$ \\
TOTAL PRODUCTION COSTS & $69,250,424$ & TOTAL INCOME & $203,200,000$ \\
\hline
\end{tabular}

As it may be seen from Table 7 and the calculations in the Supplementary Material, a maximum net benefit of EUR 100,462,182/year and a margin of profits over costs of $145 \%$ may be attained.

\subsection{Discussion of Results - Industrial Adaptation}

From the obtained results, the economic viability of the industrial implementation of a plant producing magnetic nanoparticles for hyperthermia applications seems evident. Nonetheless, it is important to notice that market demand was based on the current and foreseen demand for biomedical applications. This means that the produced particles must also be able to be used in other biomedical applications in order to reach the expected selling amount and price. The characteristics of the particles seem appropriate for this goal also (although in some cases it will probably require a further process stage for 
functionalization, but the economic margin is enough to absorb this step and maintain economic viability).

In what concerns the technological viability, the designed process seems appropriate, also considering all the mass and heat balances that were performed and the process units applied. The recovery and recycling of the raw materials after reaction is considered, as well as an appropriate recovery and purification step concerning the produced magnetic nanoparticles.

\section{Conclusions}

Hyperthermia applications of magnetic nanoparticles is currently a highly intensive field of research. Cubic-shaped magnetite particles seem to be the most promising type of particles for magnetic hyperthermia. Nonetheless, only a few studies present proper ways to obtain this type of particle, no optimization of the processes has been done, and no proper study of the influence of the main operating parameters is available in the current literature. In this work, a method for the production of cubic-shaped magnetite nanoparticles was applied and the influence of the solvent, precursor and surfactant quantities and ratio, type of solvent, stirring speed, centrifuge speed, temperature ramp-up gradient, reaction temperature, and degassing time was studied. It was concluded that increasing stirring speed is beneficial, an increase in temperature ramp-up does not affect the results, substituting the solvent (4-biphenylcarboxylic acid by benzyl ether) improves cubic form presence but increases particle size, doubling the quantities of oleic acid or 4-biphenylcarboxylic acid leads to a null production of particles, doubling the quantity of the two reactives and one of the solvents is not detrimental, reducing the degasification time is detrimental, and using both solvents at the same time (4-biphenylcarboxylic acid and benzyl ether) improves the process. The best values for the studied variables are: iron acetylacetonate (III) $-2 \mathrm{mmol}$; oleic acid $-4.5 \mathrm{mmol}$; 4 -biphenylcarboxylic acid $-2 \mathrm{mmol}$; benzyl ether $-52.5 \mathrm{mmol}$; stirring-200 rpm; reaction temperature $-290^{\circ} \mathrm{C}$; temperature ramp-up- $25^{\circ} \mathrm{C} / \mathrm{min}$; centrifugal speed-2500 rpm.

Then, the industrial implementation of a process to produce these magnetite nanoparticles based on the optimized values reached in the research stage was fully designed and studied in order to study the potential industrial implementation viability. Full process engineering, including energy and mass balances, was also conducted for the plant. The designed plant has proven to be viable economically and technically, with a maximum net benefit of EUR 100,462,182/year. Since the profit is much larger than regular bank benefits, investors may consider attractive the construction and startup of the designed industrial plant, even if several of the parameters have to be adjusted (e.g., adjustment of the sell price of the particles, estimation of some costs, etc.). It is expected that this work will serve as a demonstration of the connection between science and practical applications, and to allow scientific improvement of other processes bearing in mind their possible industrial implementation.

Supplementary Materials: The following are available online at https://www.mdpi.com/article/ 10.3390/nano11071652/s1, Figure S1: Histogram and size range of the synthesized nanomagnetic particles-Sample 1.; Figure S2: Histogram and size range of the synthesized nanomagnetic particlesSample 2.; Figure S3: Histogram and size range of the synthesized nanomagnetic particles-Sample 3.; Figure S4: Histogram and size range of the synthesized nanomagnetic particles-Sample 4.; Figure S5: Histogram and size range of the synthesized nanomagnetic particles-Sample 5.; Figure S6: Histogram and size range of the synthesized nanomagnetic particles-Sample 6.; Figure S7: Histogram and size range of the synthesized nanomagnetic particles-Sample 7.; Figure S8: Histogram and size range of the synthesized nanomagnetic particles-Sample 8.; Figure S9: Histogram and size range of the synthesized nanomagnetic particles—Sample 9.; Figure S10: Histogram and size range of the synthesized nanomagnetic particles-Sample 10.; Figure S11: Histogram and size range of the synthesized nanomagnetic particles-Sample 11.; Figure S12: Histogram and size range of the synthesized nanomagnetic particles_Sample 13.; Figure S13: Histogram and size range of the synthesized nanomagnetic particles-Sample 12 and 14.; Figure S14: Market growth for nanoparticles 
for biomedical applications.; Figure S15: Nanomedicine market growth rate until 2019.; Figure S16: Another study of the nanomedicine market until 2020.; Figure S17: Total costs/incomes versus total capacity; Table S1: Costs of Raw Materials; Table S2: Direct human labor costs.; Table S3: Labor costs for indirect human labor.; Table S4: Chief Personnel labor costs; Table S5: Management Personnel labor costs; Table S6: Streams of the Plant and their characteristics.

Author Contributions: P.A.A.: conceptualization; P.A.A. and J.M.C.: data curation; P.A.A., T.C.G. and O.S.S.: formal analysis; P.A.A., T.C.-G. and D.B.: funding acquisition; P.A.A., T.C.-G. and O.S.S.: investigation; P.A.A., T.C.-G. and O.S.S.: methodology; P.A.A., T.C.-G. and D.B.: project administration; P.A.A.: resources; P.A.A., J.M.C. and O.S.S.: software; P.A.A., T.C.-G. and D.B.: supervision; P.A.A.: validation; P.A.A. and T.C.-G.: visualization; P.A.A. and T.C.-G.: writingoriginal draft; P.A.A., T.C.-G. and D.B.: writing-review and editing. All authors have read and agreed to the published version of the manuscript.

Funding: This research was funded by: (a) Project MAT2016-76824-C3-2-R, “Diseño de Nanohilos Magneticos para su uso en Tecnologias Limpias", MINECO, Spain. (b). Base Funding-UIDB/00511/ 2020 of the Laboratory for Process Engineering, Environment, Biotechnology and Energy-LEPABEFunded by national funds through the FCT/MCTES (PIDDAC); (c). Project PTDC/QUIQFI/ 28020/2017-POCI-01-0145-FEDER-028020—Funded by FEDER funds through COMPETE2020Programa Operacional Competitividade e Internacionalização (POCI) and by national funds (PIDDAC) through FCT/MCTES.

Institutional Review Board Statement: Not applicable.

Informed Consent Statement: Not applicable.

Data Availability Statement: Not applicable.

Acknowledgments: Helena Sant'Ovaia (Instituto de Ciências da Terra-Pólo da Faculdade de Ciências U.P.) is acknowledged for all the help concerning measuring magnetic particle properties. Joaquin Moran from the Department of Organic Chemistry, University of Salamanca, Spain, is acknowledged for all the help provided.

Conflicts of Interest: The authors declare no conflict of interest.

\section{References}

1. Wild, C.; Weiderpass, E.; Steward, B. World Cancer Report: Cancer Research for Cancer Prevention; International Agency for Research on Cancer, World Health Organization: Geneva, Switzerland, 2020.

2. Bruvera, J.I. Disipación de Potencia Por Nanopartículas Magnéticas Expuestas a Campos de Radiofrecuencia Para Terapia Oncológica Por Hipertermia; Universidad Nacional de La Plata: La Plata, Argentina, 2015.

3. Horny, M.-C.; Gamby, J.; Dupuis, V.; Siaugue, J.-M. Magnetic Hyperthermia on $\gamma-\mathrm{Fe}_{2} \mathrm{O}_{3} @ \mathrm{SiO}_{2}$ Core-Shell Nanoparticles for mi-RNA 122 Detection. Nanomaterials 2021, 11, 149. [CrossRef]

4. Caizer, C. Optimization Study on Specific Loss Power in Superparamagnetic Hyperthermia with Magnetite Nanoparticles for High Efficiency in Alternative Cancer Therapy. Nanomaterials 2021, 11, 40. [CrossRef]

5. Veloso, S.R.S.; Silva, J.F.G.; Hilliou, L.; Moura, C.; Coutinho, P.J.G.; Martins, J.A.; Testa-Anta, M.; Salgueiriño, V.; CorreaDuarte, M.A.; Ferreira, P.M.T.; et al. Impact of Citrate and Lipid-Functionalized Magnetic Nanoparticles in Dehydropeptide Supramolecular Magnetogels: Properties, Design and Drug Release. Nanomaterials 2021, 11, 16. [CrossRef] [PubMed]

6. Strbak, O.; Antal, I.; Khmara, I.; Koneracka, M.; Kubovcikova, M.; Zavisova, V.; Molcan, M.; Jurikova, A.; Hnilicova, P.; Gombos, J.; et al. Influence of Dextran Molecular Weight on the Physical Properties of Magnetic Nanoparticles for Hyperthermia and MRI Applications. Nanomaterials 2020, 10, 2468. [CrossRef]

7. $\mathrm{Wu}, \mathrm{K} . ;$ Wanga, J.-P. Magnetic hyperthermia performance of magnetite nanoparticle assemblies under different driving fields. AIP Adv. 2017, 7, 056327. [CrossRef]

8. Augusto, P.A.; Castelo-Grande, T.; Vargas, D.; Pascual, A.; Hernández, L.; Estevez, A.M.; Barbosa, D. Upscale Design, Process Development, and Economic Analysis of Industrial Plants for Nanomagnetic Particle Production for Environmental and Biomedical Use. Materials 2020, 13, 2477. [CrossRef] [PubMed]

9. Augusto, P.A.; Castelo-Grande, T.; Vargas, D.; Hernández, L.; Merchán, L.; Estevez, A.M.; Gómez, J.; Compaña, J.M.; Barbosa, D. Water Decontamination with Magnetic Particles by Adsorption and Chemical Degradation. Influence of the Manufacturing Parameters. Materials 2020, 13, 2219. [CrossRef] [PubMed]

10. Li, Q.; Kartikowati, C.W.; Horie, S.; Ogi, T.; Iwaki, T.; Okuyama, K. Correlation between particle size/domain structure and magnetic properties of highly crystalline Fe3O4 nanoparticles. Sci. Rep. 2017, 7, 9894. [CrossRef]

11. Butler, R.F.; Banerjee, S.K. Theoretical single-domain grain size range in magnetite and titanomagnetite. J. Geophys. Res. 1975, 80, 4049-4058. [CrossRef] 
12. Muxworthy, A.R.; Williams, W. Critical superparamagnetic/single-domain grain sizes in interacting magnetite particles: Implications for magnetosome crystals. J. R. Soc. Interface 2009, 6, 1207-1212. [CrossRef]

13. Shah, R.R.; Davis, T.P.; Glover, A.L.; Nikles, D.E.; Brazel, C.S. Impact of magnetic field parameters and iron oxide nanoparticle properties on heat generation for use in magnetic hyperthermia. J. Magn. Magn. Mater. 2015, 387, 96-106. [CrossRef]

14. Khurshid, H.; Alonso, J.; Nemati, Z.; Phan, M.H.; Mukherjee, P.; Fdez-Gubieda, M.L.; Barandiarán, J.M.; Srikanth, H. Anisotropy effects in magnetic hyperthermia: A comparison between spherical and cubic exchange-coupled FeO/Fe3O4 nanoparticles. J. Appl. Phys. 2015, 117, 17A337. [CrossRef]

15. Avugadda, S.K.; Wickramasinghe, S.; Niculaes, D.; Ju, M.; Lak, A.; Silvestri, N.; Nitti, S.; Roy, I.; Samia, A.C.S.; Pellegrino, T. Uncovering the Magnetic Particle Imaging and Magnetic Resonance Imaging Features of Iron Oxide Nanocube Clusters. Nanomaterials 2021, 11, 62. [CrossRef] [PubMed]

16. Abenojar, E.C.; Wickramasinghe, S.; Bas-Concepcion, J.; Samia, A.C.S. Structural effects on the magnetic hyperthermia properties of iron oxide nanoparticles. Prog. Nat. Sci. Mater. Int. 2016, 26, 440-448. [CrossRef]

17. Martinez-Boubeta, C.; Simeonidis, K.; Makridis, A.; Angelakeris, M.; Iglesias, O.; Guardia, P.; Cabot, A.; Yedra, L.; Estradé, S.; Peiró, F.; et al. Learning from Nature to Improve the Heat Generation of Iron-Oxide Nanoparticles for Magnetic Hyperthermia Applications. Sci. Rep. 2013, 3, 1652. [CrossRef] [PubMed]

18. Reyes-Ortega, F.; Delgado, Á.V.; Iglesias, G.R. Modulation of theMagnetic Hyperthermia ResponseUsing Different Superparamagnetic Iron Oxide Nanoparticle Morphologies. Nanomaterials 2021, 11, 627. [CrossRef] [PubMed]

19. Augusto, P.A.; Castelo-Grande, T.; Merchan, L.; Estevez, A.M.; Quintero, X.; Barbosa, D. Landfill leachate treatment by sorption in magnetic particles: Preliminary study. Sci. Total Environ. 2019, 648, 636-668. [CrossRef] [PubMed]

20. Castelo-Grande, T.; Augusto, P.A.; Rico, J.; Marcos, J.; Iglesias, R.; Hernández, L.; Barbosa, D. Magnetic water treatment in a wastewater treatment plant: Part I-Sorption and magnetic particles. J. Environ. Manag. 2021, 281, 111872, ISSN $0301-4797$. [CrossRef]

21. Castelo-Grande, T.; Augusto, P.A.; Rico, J.; Marcos, J.; Iglesias, R.; Hernández, L.; Barbosa, D. Magnetic water treatment in a wastewater treatment plant: Part II-Processing Waters and Kinetic Study. J. Environ. Manag. 2021, acepted.

22. Hernández, L.; Augusto, P.A.; Castelo-Grande, T.; Barbosa, D. Regeneration and Reuse of Magnetic Particles for Contaminant Degradation in Water. J. Environ. Manag. 2021, acepted. [CrossRef] [PubMed]

23. Estevez, A.M.; Rodriguez, J.M.; Alvaro, A.; Augusto, P.A.; Jimenez, O.; Castelo-Grande, T.; Barbosa, D. Preparation, Characterization, and Testing of Magnetic Carriers for Arsenic Removal From Water. IEEE Trans. Magn. 2008, 44, 4436-4439. [CrossRef]

24. Kim, D.; Lee, N.; Park, M.; Hyo, B.; Kwangjin, K.; Hyeon, T. Synthesis of Uniform Ferrimagnetic Magnetite Nanocubes. J. Am. Chem. Soc. 2009, 131, 454-455. [CrossRef] [PubMed]

25. Gómez Roca, A. Preparación de Nanopartículas Magnéticas Uniformes y de Alta Cristalinidad para Biomedicina; Instituto de Ciencia de Materiales de Madrid, Departamento de Química Física I, Universidad Complutense de Madrid: Madrid, Spain, 2009. 